\title{
Experimental study of wax deposition in pipeline - effect of inhibitor and spiral flow
}

\author{
Muhammad Ali Theyab, Pedro Diaz* \\ London South Bank University, 103 Borough Rd, London SE1 OAA, UK
}

\begin{abstract}
Wax deposition is one of the main flow assurance problems in the oil industry. It can result in the restriction of crude oil flow in the pipeline, creating pressure abnormalities and causing an artificial blockage leading to a reduction or interruption in the production. Wax can precipitate as a solid phase on the pipe wall when its temperature (inlet coolant temperature) drops below the Wax Appearance Temperature (WAT). An experimental flow loop system was built in the lab to study the variation of wax deposition thickness under the single phase transport. A series of experiments were carried out at different flow rates $(2.7$ and $4.8 \mathrm{~L} / \mathrm{min})$ to study wax deposition and measure the wax thickness using four different techniques including direct technique pigging, pressure drop, heat transfer and Liquid Displacement-Level Detection (LD-LD). The effect of factors on wax formation such as inlet coolant temperature, inhibitor and spiral flow has been examined. The results show the wax inhibition percentage (WI) $\%$ was $40 \%$ and $45 \%$ at flow rate 2.7 and $4.8 \mathrm{~L} / \mathrm{min}$ respectively of the inhibitor W802 (polyacrylate polymer (C16-C22)) at inlet coolant temperature $14{ }^{\circ} \mathrm{C}$. The wax reduction percentage (WR) $\%$ was $65 \%$ and $73 \%$ at flow rate 2.7 and $4.8 \mathrm{~L} / \mathrm{min}$ respectively of the spiral flow at inlet coolant temperature $14{ }^{\circ} \mathrm{C}$. This percentage of inhibition will increased rapidly by increasing the inlet coolant temperature.
\end{abstract}

Keywords: Wax inhibitor, spiral flow, wax inhibition, wax measuring techniques

\section{Introduction}

Wax deposition is one of the main flow assurance problems in the oil industry. Wax deposition can result in the restriction of crude oil flow in the pipeline, creating pressure abnormalities and causing an artificial blockage leading to a reduction or interruption in the production. However, in an extreme case, this can cause a pipeline or production facility to be abandoned [1]. Wax can precipitate and arise when paraffin components in crude oil precipitate and deposit on the cold pipeline wall when the inner wall temperature (inlet coolant temperature) drops below the wax appearance temperature [2]-[4]. Wax Appearance Temperature (WAT) is the temperature at which paraffin wax start to precipitate [5].

Time (2011) [6] mentioned that the solid phase of wax begins to precipitate characteristically around 30 to $40^{\circ} \mathrm{C}$, but may possibly be as high as 50 to $55^{\circ} \mathrm{C}$ [6]. The main factor that affects the wax deposition process is the low temperature, which means that subsea pipelines are especially vulnerable. Therefore, wax deposition prevention becomes very important in deep- water oil production.

Wax deposition in crude oil production systems can be reduced or prevented by one or combination of chemical, mechanical, and thermal remediation methods. However, with the advent of extremely deep production, offshore drilling and ocean floor completions, the use of mechanical and thermal remediation methods becomes prohibitive economically; as a result, the use of chemical additives as wax deposition inhibitors is becoming more prevalent [7]. Selected chemical inhibitor was tested in the current work to study its effect on wax deposition. Wax deposition experiments are carried out at different flow rates 2.7 and $4.8 \mathrm{~L} / \mathrm{min}$., to study the influence of factors that affect the formation of wax deposits such as inlet

\footnotetext{
${ }^{*}$ Manuscript received March 11, 2016; revised July 30, 2016.

Corresponding author. Tel.: +447833846288; E-mail address: theyabm@1sbu.ac.uk

doi: $10.12720 /$ sgce $5.3 .174-181$
} 
coolant temperature, inhibitor W802 polyacrylate polymer (C16-C22) and spiral flow. Four different techniques were used to measure wax thickness including pigging, pressure drop, heat transfer and liquid displacement-level detection (LD-LD).

This study shows a comparison between the techniques for measuring wax thickness; and a comparison between the mitigation techniques to reduce wax thickness.

\section{Experimental Methodology}

\subsection{Characterization of crude oil}

The crude oil that has been used in this study is one of the oil fields reservoirs with waxing problems in the extreme north eastern part of India. All the crude oil characterization was carried out in the lab following the standards analytical methods as shown in Table 1.

Table 1. Crude oil characteristics

\begin{tabular}{|l|l|l|l|}
\hline Characteristics & Unit & Value & Experimental Method \\
\hline Density & $\mathrm{kg} / \mathrm{m}^{3}\left(15^{\circ} \mathrm{C}\right)$ & 850 & mass/volume \\
\hline Sp. Gravity & $60 / 60^{\circ} \mathrm{F}$ & 0.85 & Calculated \\
\hline API Gravity & $60^{\circ} \mathrm{F}$ & 34.97 & API Method \\
\hline WAT at shear rate $101 / \mathrm{s}$ & ${ }^{\circ} \mathrm{C}$ & 39 & Rheometer \\
\hline WAT at shear rate $1201 / \mathrm{s}$ & ${ }^{\circ} \mathrm{C}$ & 30 & Rheometer \\
\hline Pour Point & ${ }^{\circ} \mathrm{C}$ & 27.6 & Rheometer \\
\hline Wax Content & $\mathrm{wt} \%$ & 20.15 & ASTM D721 \\
\hline Saturates & $\mathrm{wt} \%$ & 74.91 & SARA \\
\hline Aromatics & $\mathrm{wt} \%$ & 20.44 & SARA \\
\hline Resins & $\mathrm{wt} \%$ & 4.26 & SARA \\
\hline Asphaltene & $\mathrm{wt} \%$ & 0.39 & SARA \\
\hline
\end{tabular}

\subsection{Experimental methodology of wax deposition}

Regarding to study wax deposition process, the waxy crude oil was pumped through the inner pipe at a relatively higher temperature than the wall coolant temperature, to create the appropriate environment for the deposition inside the test section. The pressure drop along the length of the pipe was then measured. Experiments for different flow rates $(2.7$ and $4.8 \mathrm{~L} / \mathrm{min})$ were carried out, with and without inhibitors, with and without spiral flow at different aging time (2, 4, and $6 \mathrm{hr})$, and different coolant temperature (14, 24,33 , and 40C). The general research strategies that outline the way to determine the parameters which affect the wax deposition are included:

- Study the influence of some factors on wax deposit such as inlet coolant temperature, inhibitor (W802) and spiral flow, to build a wide understanding of the wax deposition process.

- Study the dependence of wax deposition on inlet coolant temperatures by carrying out the experiments at the same flow rate, same oil temperature, but at different coolant temperature.

- Study the influence of the inhibitor polyacrylate based polymer (C16-C22) on wax deposition.

- Evaluation the effect of spiral flow on wax deposition.

\subsection{Wax deposition experimental rig design}

An experimental rig was built in the lab to study wax deposition process under the single phase transport and measuring wax thickness using the pressure drop method, pigging method, heat transfer method and LD-LD method. This rig, as shown in Fig. 1, is consist of high thermal conductivity of copper pipe provides the opportunity for more wax precipitation during a short time compared with other metals. This will also provide advantage to quick formation of wax in the copper pipe (for the purpose of studying wax thickness) due to high heat exchange through the pipe wall. 


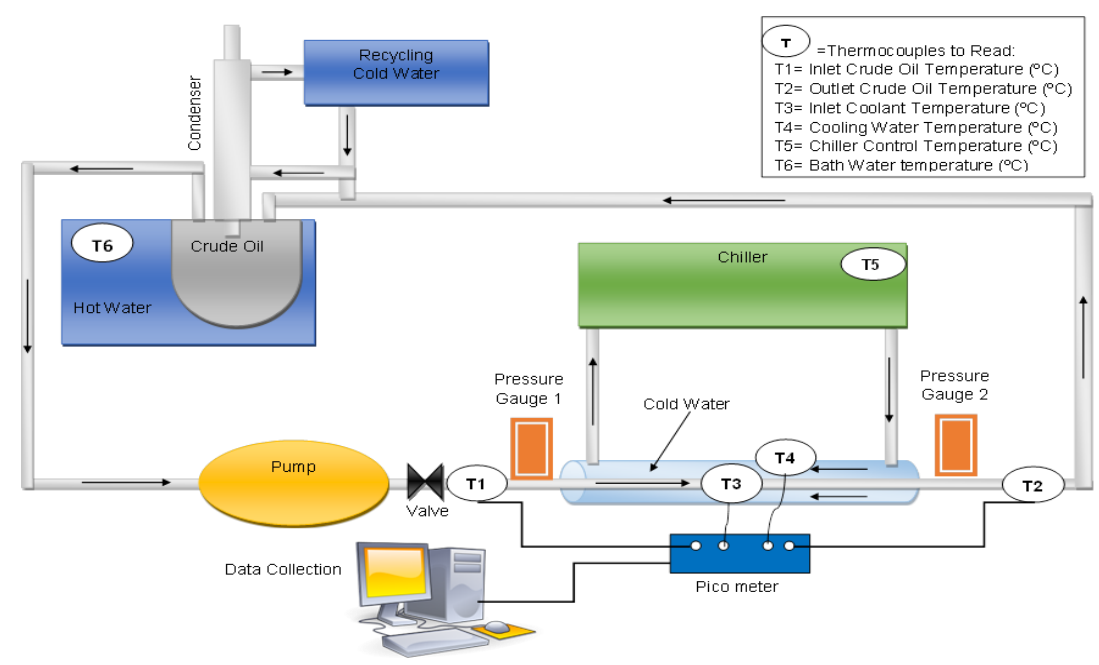

Fig. 1. Schematic of wax deposition test flow loop designe $\mathrm{d}$ in this study.

\subsection{Techniques for measuring wax thickness}

Four different techniques have been used in this work to measure wax deposit thickness inside the pipe. These techniques are called pigging method, pressure drop, heat transfer and liquid displacement-level detection (LD-LD).

Pigging technique is based on the concept of passing spheres through the test section and measuring the wax volume removed [8]. This method is direct and simple, because it is providing a visual examination of the wax deposit.

Pressure drop technique is based on the concept that wax deposition in a pipe section reduces the hydraulic diameter of the flowing fluid inside the pipe, resulting in an increase in frictional pressure drop over the pipe section [2], [8]. The wax thickness present in the pipe wall can be calculated accurately from the following equation presented by Chen et al, (1997) [8]:

$$
\left(d_{i}-2 \delta_{w}\right)^{5-n}=\frac{2 c \rho L}{\Delta p_{f}}\left(\frac{\mu}{\rho}\right)\left(\frac{4 Q}{\pi}\right)^{2-n}
$$

where $\Delta p_{f}$ is the pressure drop, $L$ is the length of pipe section, $d$ is the hydraulic diameter or effective inside diameter, $Q$ is the volumetric flow rate, $\rho$ is the fluid density, where $\mu$ is the apparent viscosity of the crude oil. $c=16, n=1$ for laminar flow and $c=0.046, n=0.2$ for turbulent flow. Laminar flow exists when $\mathrm{NRe}<2000$, [8]. Heat transfer technique based on the concept that a thermal resistance term due to heat conduction through the wax layer is added to the total resistance to heat transfer from the flowing fluid to the environment. The wax thickness can be measured from the heat transfer equation.

$$
\frac{T_{f}-T_{o}}{q_{o}}=\frac{1}{h_{w}} \frac{r_{o}}{r_{i}-\delta_{w}}+\frac{r_{o}}{k_{w}} \ln \frac{r_{i}}{r_{i}-\delta_{w}}+\frac{r_{o}}{k_{p}} \ln \frac{r_{o}}{r_{i}}
$$

where $T_{f}$ is the bulk fluid temperature in the pipe, $T_{o}$ is the outside pipe wall temperature, $q_{o}$ is the heat flux through the outside pipe wall, $r_{o}$ and $r_{i}$ are the outside and inside diameters of the pipe, respectively, $h_{w}$ is the film heat transfer coefficient from the flowing fluid to the wax layer, $k_{p}$ and $k_{w}$ are the thermal conductivities of the pipe wall and deposited wax, respectively, and $\delta_{w}$ is the thickness of wax layer [8]. 
Liquid Displacement-Level Detection (LD-LD) technique measured the change in the volume of a removable pipe section before and after wax deposition [2], [8]. In the current research, the test section of the pipe was displaced with water before run the experiment and after wax deposit in the pipe. The difference between the two volumes is representing the wax volume.

\section{Results and Discussion}

\subsection{Measuring wax thickness at different techniques}

The four previous techniques have been used to evaluate the wax thickness in the test section of the pipe. Table 2, and Table 3 shows a comparison between the techniques to estimate the wax thickness at different flow rates. The results show a large correspond between the wax volumes measured during the pigging method and LD-LD method, this is illustrate the validity of the methods. The pressure drop method and heat transfer method are shows a similarity in the results at high pressure drop and slightly different at lower pressure drop at the same flow rate.

Table 2. Measuring wax thickness $\left(\delta_{w}\right)$ using different techniques at flow rate $2.7 \mathrm{~L} / \mathrm{min}$

\begin{tabular}{|c|c|c|c|c|c|c|c|}
\hline $\begin{array}{l}\text { Coolant } \\
\text { Temp. }\left({ }^{\circ} \mathrm{C}\right)\end{array}$ & $\begin{array}{c}\text { Pressure } \\
\text { Drop(Pa) }\end{array}$ & $\begin{array}{l}\text { Exp. Wax } \\
\text { Volume(ml) }\end{array}$ & $\begin{array}{c}\text { Wax Volume } \\
(\mathrm{ml}) \text { LD-LD }\end{array}$ & $\begin{array}{c}\delta_{w} \mathrm{~mm} \text { (Pigging } \\
\text { Method) }\end{array}$ & $\begin{array}{c}\delta_{w} \mathrm{~mm} \text { (Pressure } \\
\text { Drop) }\end{array}$ & $\begin{array}{c}\delta_{w} \mathrm{~mm}(\mathrm{Heat} \\
\text { Transfer) }\end{array}$ & $\begin{array}{c}\delta_{w} \mathrm{~mm} \\
(\mathrm{LD}-\mathrm{LD})\end{array}$ \\
\hline 14 & 1200 & 125 & 126 & 1.82 & 1.83 & 1.83 & 1.84 \\
\hline 24 & 1000 & 83 & 83 & 1.5 & 1.61 & 1.3 & 1.5 \\
\hline 33 & 900 & 19 & 20 & 0.7 & 0.69 & 0.71 & 0.73 \\
\hline 40 & 600 & 0 & 0 & 0 & 0.04 & 0.06 & 0 \\
\hline
\end{tabular}

Table 3. Measuring wax thickness $\left(\delta_{w}\right)$ using different techniques at flow rate $4.8 \mathrm{~L} / \mathrm{min}$

\begin{tabular}{|l|l|l|l|l|l|l|l|}
\hline $\begin{array}{l}\text { Coolant } \\
\text { Temp. }\left({ }^{\circ} \mathrm{C}\right)\end{array}$ & $\begin{array}{l}\text { Pressure } \\
\text { Drop }(\mathrm{Pa})\end{array}$ & $\begin{array}{l}\text { Exp. Wax } \\
\text { Volume }(\mathrm{ml})\end{array}$ & $\begin{array}{l}\text { Wax Volume } \\
(\mathrm{ml}) \text { LD-LD }\end{array}$ & $\begin{array}{l}\delta_{w} \mathrm{~mm} \text { (Pigging } \\
\text { Method) }\end{array}$ & $\begin{array}{l}\delta_{w} \mathrm{~mm} \text { (Pressure } \\
\text { Drop) }\end{array}$ & $\begin{array}{c}\delta_{w} \mathrm{~mm}(\mathrm{Heat} \\
\text { Transfer) }\end{array}$ & $\begin{array}{c}\delta_{w} \mathrm{~mm} \\
(\mathrm{LDLD})\end{array}$ \\
\hline 14 & 3000 & 85 & 87 & 1.5 & 1.72 & 1.72 & 1.52 \\
\hline 24 & 2700 & 70 & 70 & 1.36 & 1.45 & 1.27 & 1.36 \\
\hline 33 & 2100 & 15 & 17 & 0.63 & 0.79 & 0.65 & 0.67 \\
\hline 40 & 1200 & 0 & 0 & 0 & 0.054 & 0 & 0 \\
\hline
\end{tabular}

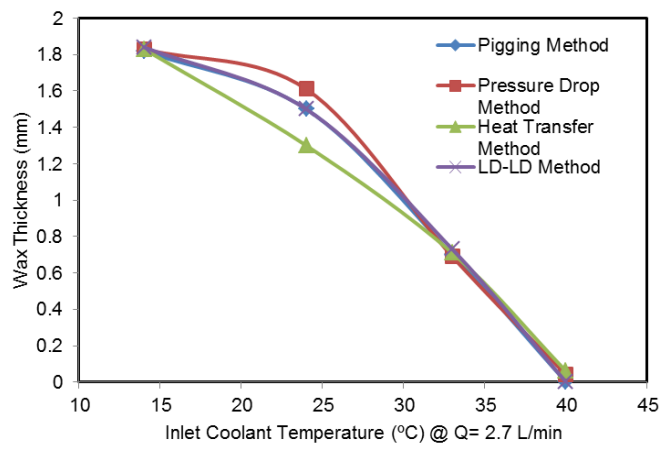

(a)

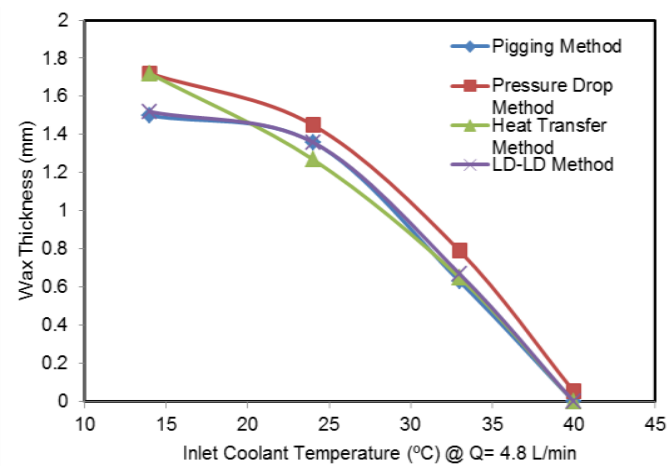

(b)

Fig. 2. The effect of inlet coolant temperature on wax thickness at different flow rates (a) $2.7 \mathrm{~L} / \mathrm{min}$ (b) $4.8 \mathrm{~L} / \mathrm{min}$, and different techniques.

\subsection{Effect of inlet coolant temperature}

In this study, it was observed that the inlet coolant temperature affects the wax deposition inside the 
pipe. During run the experiments, it was noted that the deposit thickness is increased with decreasing the inlet coolant temperature even when was the crude oil temperature above wax appearance temperature, that means wax deposition depend on the inlet coolant temperature more than it depend on the crude oil temperature. Wax thickness increased to $1.83 \mathrm{~mm}$ at the end of the experiment when the inlet coolant temperature was equal to $14^{\circ} \mathrm{C}$.

The wax thickness decreased when the inlet coolant temperature increased $\left(24,33,40^{\circ} \mathrm{C}\right)$ respectively and stopped to precipitate at $40^{\circ} \mathrm{C}$ as shown in Fig. 2, where this temperature is above wax appearance temperature.

\subsection{Effect of inhibitor on wax thickness}

The performance of some of wax inhibitors was evaluated at concentration 1000ppm to determine their effects on the wax precipitation using the Bohlin Gemini II Rheometer. The effect was appeared on the wax appearance temperature and the viscosity of the crude oil.

The analysis of the crude oil with the inhibitors shows that the inhibitor W802 (polyacrylate polymer (C16-C22)) produced the greatest reduction in viscosity, which means reduction in the wax appearance temperature. This inhibitor has been used to study its effect on the wax deposition at different flow rates (2.7 and $4.8 \mathrm{~L} / \mathrm{min}$ ).

Fig. 3 shows that the inhibitor reduced the wax thickness at flow rate $2.7 \mathrm{~L} / \mathrm{min}$ and inlet coolant temperature $14{ }^{\circ} \mathrm{C}$ from $1.86 \mathrm{~mm}$ to $1.42 \mathrm{~mm}$, this consider a great reduction at this low temperature. Also, it reduced the wax thickness from $1.63 \mathrm{~mm}$ to $1.3 \mathrm{~mm}$ at flow rate $4.8 \mathrm{~L} / \mathrm{min}$ and inlet coolant temperature $14^{\circ} \mathrm{C}$.

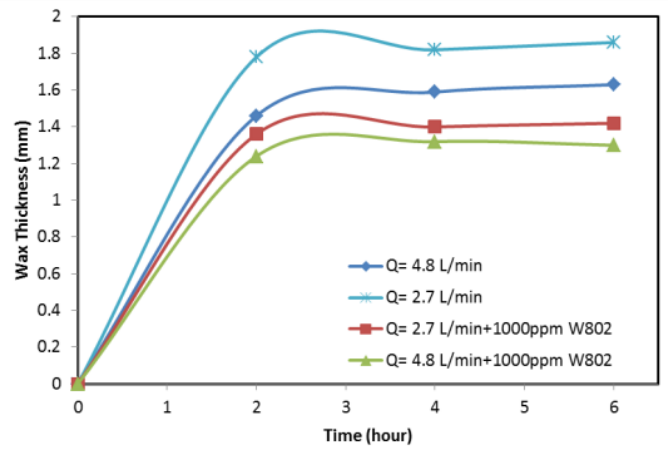

Fig. 3. The effect of inhibitor W802 on wax thickness at 2.7 and $4.8 / \mathrm{min}$, at inlet temperature $14{ }^{\circ} \mathrm{C}$.

The inhibitor has been used in the current work are based on polymers which are normally used as pour point depressant. The reduction in the pour point and the crude oil viscosity had been making the transportation of the crude oil easier [9], [7]. This inhibitor was reducing the wax deposition process by interfering with wax crystallization and growth process. However, this interfering mechanism has not yet been fully understood [10].

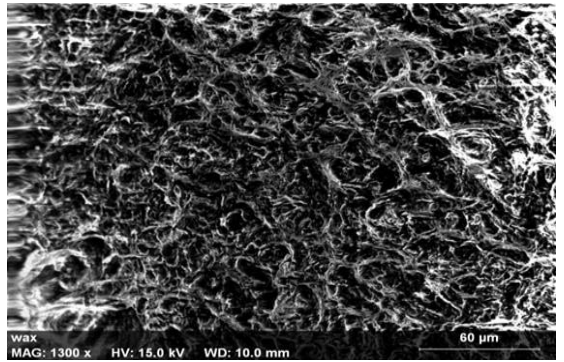

(a)

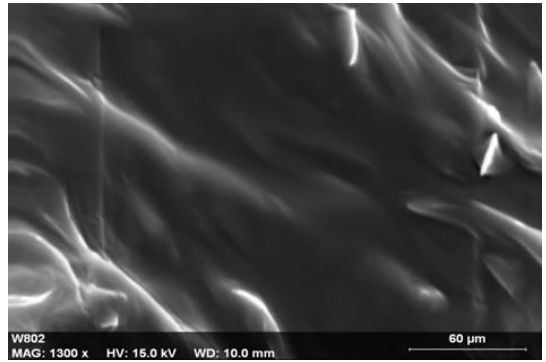

(b)

Fig. 4. The structure of wax before (a) and after (b) adding the inhibitor W802 using SEM. 
The effect of the inhibitor on wax structure have been examined using the Scanning Electron Microscopy (SEM) as shown in Fig. 4, where it can be seen the clearly how the inhibitor effect and changed the wax structure. This change can be illustrated as wax inhibitor polymers containing similar structure to the wax structure, thereby allowing the inhibitor crystal to be incorporated into the wax crystal growth. Sometimes the structural part of the polymer covers the wax site, thereby preventing further wax crystal growth and promoting the formation of smaller wax aggregates [10], [7].

\subsection{Effect of spiral flow on wax thickness}

In this study, spiral flow was used to mitigate wax deposition inside the pipe; this kind of flow was created by insert a thin twisted aluminium plate inside the test section of pipe and equal to pipe length. In this case the spiral flow was created and examined in the rig, where the experiments were carried out at different flow rates, different coolant temperatures, and different times. During carrying out the experiments it was noticed that the pressure drop along the pipe was huge, due to the twisted plate inside the pipe where the crude oil flow will take long time compare with the flow in the pipe without twisted plate. In this case, the shear stress will be high due to increase the velocity of the flow, and the force of the shear stress will be higher than the force of wax deposition and it prevents wax crystal growth.

On another hand, it was noticed that the temperature drop of the crude oil along the test pipe was double compare with the temperature drop of the crude oil without twisted plate. This drop in temperature happened due to increase the length of the crude oil flow, where it leading to loss temperature to surrounding. Despite of increasing both of the pressure drop and the temperature drop, the volume of the wax deposit inside the pipe was lower comparing with the wax volumes of the experiments with laminar or turbulent flow, because of the spiral flow increased the shear stress inside the pipe.

The spiral flow prevents wax deposition in the pipe where it was reduced the wax thickness from 1.86 to $1.07 \mathrm{~mm}$ at inlet coolant temperature $14 \mathrm{C}$, flow rate $2.7 \mathrm{~L} / \mathrm{min}$ and 6 hours the time of the experiment. While, the reduction in wax thickness at inlet coolant temperature $14 \mathrm{C}$, flow rate $4.8 \mathrm{~L} / \mathrm{min}$ and same experiment period, was from 1.63 to $0.85 \mathrm{~mm}$ as shown in Fig. 5 .

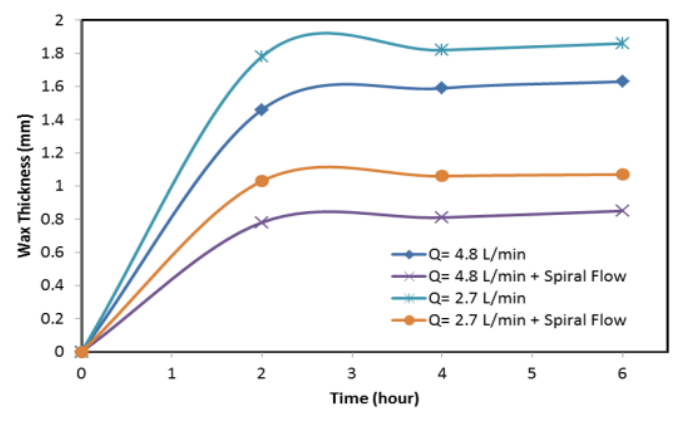

Fig. 5. The effects of spiral flow on wax thickness at different flow rates.

\subsection{Evaluation of wax inhibition}

Wax Inhibition WI (\%): The ratio of the difference of wax deposition rate with and without inhibitor to that of the blank oil at a specific temperature [7].

$$
W I(\%)=100 \frac{W_{b}-W_{w i}}{W_{b}}
$$

$W_{b}=$ Wax deposit by volume of the blank oil (ml), $W_{w i}=$ Wax deposit by volume during the same period of time treated oil $(\mathrm{ml})$.

Wax Reduction WR (\%): The ratio of the difference of wax deposition rate with and without spiral flow to that of the blank oil at a specific temperature. 
$W R(\%)=100 \frac{W_{b}-W_{w s}}{W_{b}}$

$W_{w s}=$ Wax deposit volume during use the spiral flow $(\mathrm{ml})$.

Fig. 6, shows the wax inhibition percentage (WI)\% of inhibitor W802 and wax reduction percentage (WR)\% of spiral flow, where at flow rate $2.7 \mathrm{~L} / \mathrm{min}$, inlet coolant temperature $14{ }^{\circ} \mathrm{C}$ and $1000 \mathrm{ppm}$ inhibitor W802, the wax inhibition percentage was $40 \%$ while with the spiral flow was $65 \%$. At flow rate $4.8 \mathrm{~L} / \mathrm{min}$, inlet coolant temperature $14{ }^{\circ} \mathrm{C}$ and $1000 \mathrm{ppm}$ inhibitor $\mathrm{W} 802$, the wax inhibition percentage was $45 \%$ while with the spiral flow was $73 \%$. This percentage of inhibition will increased rapidly by increasing the the inlet coolant temperature.

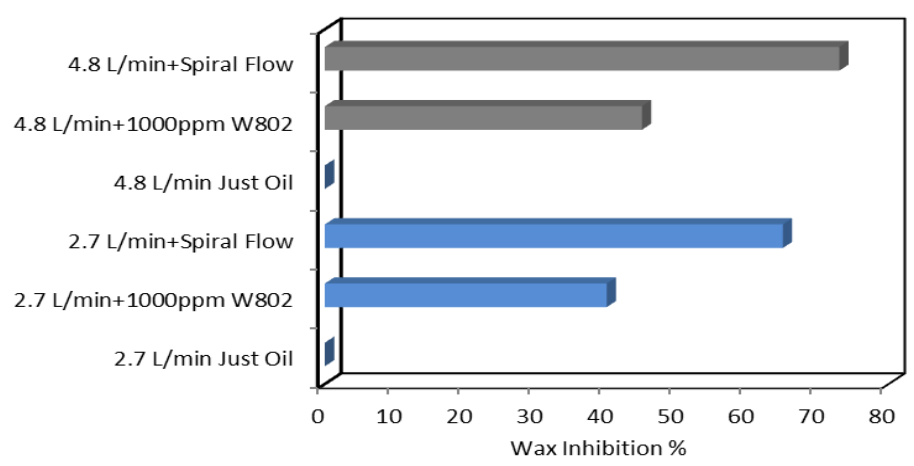

Fig. 6. Wax inhibition \% of the inhibitor W802 and spiral flow.

\section{Conclusion}

Wax can precipitate as a solid phase on the pipe wall when its temperature drops below the WAT. It results in the restriction of crude oil flow in the pipeline, creating pressure abnormalities and causing an artificial blockage leading to a reduction or interruption in the production.

An experimental rig was designed to study wax deposition process and study some parameters that influence on the wax formation such as inlet coolant temperature, inhibitor and spiral flow. Four different techniques have been used to evaluate the wax thickness in the test section of pipe include pigging, pressure drop, heat transfer and liquid displacement-level detection.

Two mechanisms had been used to mitigate wax deposition, inhibitor W802 (polyacrylate polymer (C16-C22)) and spiral flow where created by inserting a thin twisted aluminum plate in the test section of the pipe.

The results show that wax deposit increases with decreasing the inlet coolant temperature, and decreases and stops above WAT. The results show the wax inhibition percentage (WI)\% was $40 \%$ and $45 \%$ at flow rate 2.7 and $4.8 \mathrm{~L} / \mathrm{min}$ respectively of the inhibitor $\mathrm{W} 802$ (polyacrylate polymer (C16-C22)) at inlet coolant temperature $14^{\circ} \mathrm{C}$. The wax reduction percentage (WR) $\%$ was $65 \%$ and $73 \%$ at flow rate 2.7 and $4.8 \mathrm{~L} / \mathrm{min}$ respectively of the spiral flow at inlet coolant temperature $14^{\circ} \mathrm{C}$.

It can be concluded that the chemical inhibitor and the spiral flow work efficiently to mitigate wax deposition, but the spiral flow presented better results due to increasing shear stress inside the pipe.

This technique of creating spiral flow by using twist material inside the pipe will provide a potential mechanism to reduce waxing.

\section{Acknowledgement}

The authors would like to thank the Ministry of Higher Education and Scientific Research/Iraq for the financial support. We would like to thank Dr Issa Chaer, Dr Nick Power from London South Bank University and Miss Heather Blackwood from Roemex Limited Company, for them helps. 


\section{References}

[1] Singh, A, Lee H, Singh, P, Sarica, C. SS: Flow assurance: Validation of wax deposition models using field data from a subsea pipeline. In: Proc. of Offshore Technology Conference, 2011:1-19.

[2] Huang, Z, Zheng, S, Fogler, HS. Wax Deposition: Experimental Characterizations, Theoretical Modeling, and Field Practices. 1 st ed. Boca Raton, London, New York: Taylor \& Francis Group; 2015.

[3] Adeyanju OA, Oyekunle LO. Experimental study of wax deposition in a single phase sub-cooled oil pipelines. Presented at: 2013 NAICE.

[4] Lee HS. PhD Dissertation. Computational and Rheological Study of Wax Deposition and Gelation in Subsea Pipelines. University of Michigan; 2008.

[5] Tordal A. (2006). Pigging Of Pipelines with High Wax Content. [Online] Available: http://www.ppsaonline.com/papers/2006Aberdeen-1-Tordal.pdf

[6] Time RW. (May 2011). Flow Assurance and Multiphase Flow (Part II). [Online]. Available: http://citrix.akersolutions.com/PageFiles/12184/Flow\%20assurance\%20presentation\%20-\%20Rune\%20Time\%202.pdf

[7] Adeyanju OA, Oyekunle LO. Influence of long chain acrylate ester polymers as wax inhibitors in crude oil pipelines. In: Proc. of SPE Nigeria Annual International Conference and Exhibition, 2014:1-13.

[8] Chen XT, Volk BM, Bwith SP, rill JP. Techniques for measuring wax thickness during single and multiphase flow. In: Proc. SPE Annual Technical Conference and Exhibition, 1997:249-256.

[9] Pedersen KS, Ronningsen HP. Influence of wax inhibitors on wax appearance temperature, pour point, and viscosity of waxy crude oils. Energy and Fuels, 2003; 17(2): 321-328.

[10] Jennings DW, Newberry ME. Paraffin inhibitor applications in deepwater offshore development. In: Proc. of International Petroleum Technology Conference, 2008:1-14. 